\title{
DISPONIBILIDADE HÍDRICA E GERMINAÇÃO DE SEMENTES DE CEBOLA (Allium cepa L.)
}

\author{
Z. PIANA \\ EPAGRI, C.P. 502, CEP: 88034-901 - Florlan6polls,SC \\ C. CAVARIANI \\ Departamento de Ciencia do Solo - FCA/UNESP, C.P. 237, CEP:16800-970 - Botucatu,SP \\ M.A.A. TILLMANN \\ Departamento de Fütotecnia - FAEM/UFPEL - C.P. 354, CEP: 96010-970 - Pelotas, RS \\ K. MINAMI \\ Departamento de Horticultura - ESALQ/USP, C.P. 9, CEP: 13418-900 - Piracicaba,SP.
}

\begin{abstract}
RESUMO: Objetivando verificar a influência do teor de água do substrato na germinação de sementes de cebola (Allium cepa $L_{\text {.) }}$, conduxiu-se um ensaio sob condiçôes de ambiente de laboratório. Os efeitos de cinco níveis de água no substrato solo $x$ areia (3:1), 20, 40, 60, 80 e 100\% da capacidade de retenção foram avaliados através da porcentagem de emergência no $\mathbf{1 4}^{\circ}$ dia da semeadura e pesos da matéria verde e seca das plântulas normais. Para tanto, 200 sementes do cultivar Pira Ouro por tratamento, em quatro repetiçoes de 50, foram semeadas a $1,5 \mathrm{~cm}$ de profumdidade, mantendo-se constantes os níveis de água no substrato. Os resultados possibilitaram concluir que os níveis de umidade do solo indicados para germinação de sementes de cebola são de $40 \%$ e $60 \%$ da capacidade de retenção do substrato, por possibilitarem uma melhor emergência, peso da matéria verde e seca das plântulas.

Descritores: sementes, água, germinação, cebola
\end{abstract}

\section{WATER AVAILARILITY AND GERMINATION OF ONION SEEDS (Allium cepa L.)}

\begin{abstract}
ARSTRACT: One essay was conducted under laboratory conditions, in order to verify the influence of substrate water content on the germination of onion (Allium cepa $L$.) seeds. The effect of five water levels in the medium soil $x$ sand $(3: 1)-20,40,60,80$ and $100 \%$ retention capacity-were evaluated through the emergence percentage 14 days after seedling and the weight of fresh and dry matters of normal seedlings. For that purpose, 200 treated seeds of Pira Ouro cultivar were sown $1.5 \mathrm{~cm}$ deep in four replications of 50 , with a constant water content in the medium. The best results showed that the soil moisture levels suggested for the germination of onion seeds were $40 \%$ to $60 \%$ of the substrate retention capacity, once they provide better emergence, weight of the fresh and dry matters of seedlings.
\end{abstract}

Key Words: seeds, water, germination, onion

\section{INTRODUÇÃO}

A água é a substância mais abundante encontrada nas plantas, sendo permanentemente detectável nas relações dinâmicas entre o solo, as plantas e a atmosfera. No entanto, sob condições de campo, o suprimento de água pode ser às vezes inadequado para satisfazer o desenvolvimento das plantas.

A importância da água é permanente durante todo o ciclo da planta, embora possam ser reconhecidos periodos críticos de maior dependência. Nas plantas multiplicadas por semente, a fase de estabelecimento em campo, representada pela germinação e pela emergência das plântulas, define um ponto de retorno produtivo, de estreita dependência da disponibilidade hídrica.

Para a quase totalidade das espécies cultivadas, o período compreendido entre a semeadura e a emergência das plântulas representa uma das fases críticas do ciclo de plantas, de modo que a uniformidade e a porcentagem de emergência assumem grande importância na produção e qualidade final do produto. A água é o fator que exerce a mais determinante influência sobre o processo de germinação (CARVALHO \& NAKAGAWA, 1983), devendo estar disponível para as sementes num teor adequado.

Em termos de estabelecimento das plântulas no campo, tanto o excesso como défice 
hídricos são desfavoráveis (BRADFORD, 1986). 0 excesso ou falta de água, representam situações em que os problemas fitopatológicos podem se agravar nas sementes em germinação. No primeiro caso, a embebição, demasiadamente rápida, reduz o período disponivel para que as membranas celulares se reorganizem e, como consequência, há uma expressiva liberação de solutos que passam a agir como substrato para os microorganismos presentes no ambiente (PESKE \& DELOUCHE, 1985); no segundo caso, o retardamento na germinação e na emergência, proporcionam ampliação no tempo de exposição à ação dos patógenos (MARCOS FILHO, 1986), acarretando prejuizos ao desempenho das sementes (HUNTER \& ERICKSON, 1952).

Os efeitos da disponibilidade hídrica se prolongam após a emergência do eixo embrionário, com reflexos sobre o desenvolvimento das plântulas. De maneira geral, a carência hídrica promove prejuízos tanto à raíz quanto à parte aérea (YOUNG et al., 1983; SILVA, 1989). Por outro lado, o excesso hídrico também é prejudicial à germinação por restringir o oxigênio, ou por causar danos embrionários provocados por embebição demasiadamente rápida (PESKE \& DELOUCHE, 1985). A expressão dos citados prejuízos, tem sido revelada por retardamento do desenvolvimento radicular (GRABE \& DANIELSON, 1965), e elevação da incidência de microorganismos nas sementes em germinação (NORTON, 1986).

Em relação ao teor de água do substrato para a germinação de sementes, as regras para Análise de Sementes (BRASIL, 1992) indicam umidade do substrato areia de $50 \%$ da capacidade de retenção para as sementes de gramíneas, exceto milho, e de $60 \%$ dessa capacidade para as sementes de leguminosas e milho. Para o substrato solo, não há indicação em termos porcentuais. Não há também, citação para o caso particular de sementes de cebola.

É notada carência de pesquisas que associem efeitos da disponibilidade hídrica no solo e a germinação das sementes (YOUNG et al., 1983). Assim, este trabalho teve como objetivo verificar a influência do teor de água do substrato, na germinação de sementes de cebola.

\section{MATERIAL E MÉTODOS}

O experimento foi conduzido sob condições ambientais do Laboratório de Análise de Sementes, da Escola Superior de Agricultura "Luiz de Queiroz"/USP - Piracicaba - SP. Foram definidos cinco tratamentos, correspondentes aos teores de água no substrato solo $\mathrm{x}$ areia (3:1) de $20,40,60,80$ e $100 \%$ da capacidade de retenção, determinados conforme metodologia descrita por FRETZ et al. (1979), constando de quatro repetições. $O$ controle da umidade foi executado diariamente, durante todo o período experimental, através de pesagens do substrato, com reposição de água quando necessário, mantendo-se a umidade nos níveis indicados.

Foram utilizadas sementes de cebola, do cultivar Pira Ouro, com $94 \%$ de germinação, previamente avaliadas de acorto com BRASIL (1992). Cada repetição continha 50 sementes, as quais foram semeadas em caixas gerbox a $1,5 \mathrm{~cm}$ de profundidade, perfazendo 200 sementes por tratamento.

Os efeitos dos diversos teores de água no substrato sobre a emergência foram avaliados através dos seguintes parâmetros: porcentagem de emergência e peso da matéria verde e seca das plântulas normais.

Os dados de porcentagem de emergência foram obtidos no $14^{\circ}$ dia após semeadura, envolvendo o número de plântulas normais estabelecidas. As mesmas plântulas normais de cada parcela foram seccionadas através do substrato, acondicionadas em embalagens plásticas resistentes a troca de umidade, e imediatamente pesadas, obtendo-se o peso da matéria verde total das plântulas em gramas. Para o peso da matéria seca, as mesmas plântulas foram transferidas para embalagens porosas de papel e secas a $70^{\circ} \mathrm{C}$ até peso constante, seguida de pesagens, expressandose os resultados em gramas.

Adotou-se o delineamento experimental inteiramente casualizado, sendo os resultados submetidos à análise de variância (teste F), comparando-se as médias pelo teste Tukey, no nível de $1 \%$ de probabilidade. Os resultados foram também interpretados através de análise de regressão.

\section{RESULTADOS E DISCUSSÃO}

Pelos resultados obtidos no teste de emergência (TABELA 1), observou-se melhor desempenho das sementes de cebola nos níveis de umidade do substrato de 20 e $40 \%$ da capacidade de retenção. $O$ nível de $60 \%$, também possibilitou elevada taxa de emergência.

A regressão da \% de emergência (y) em função dos níveis de umidade (x) é:

$$
y=72,7+1,2892 x-0,0206 x^{2}
$$


TABELA 1 - Dados de porcentagem de emergência, peso da matéria verde e peso da matéria seca de plântulas de cebola, no $14^{\circ}$ dia após a semeadura, em diferentes níveis de umidade do substrato (solo $\mathrm{x}$ areia $-3: 1$ ), relativos à média de 4 repetições de 100 sementes.

\begin{tabular}{|c|c|c|c|c|}
\hline \multirow[b]{2}{*}{$n^{0}$} & \multicolumn{4}{|l|}{ Tratamentos } \\
\hline & $\begin{array}{c}\text { Níveis de umidade }{ }^{1} \\
(\%)\end{array}$ & $\begin{array}{c}\text { Emergência } \\
(\%)\end{array}$ & $\begin{array}{l}\text { Peso da matéria verde } \\
(\mathrm{g})\end{array}$ & $\begin{array}{c}\text { Peso da matéria seca } \\
(\mathrm{g})\end{array}$ \\
\hline 1 & 20 & $89,0 \mathrm{ab}$ & $0,346 c$ & $0,050 \mathrm{~b}$ \\
\hline 2 & 40 & 91,5 a & $0,705 b$ & $0,054 a b$ \\
\hline 3 & 60 & $83,5 b$ & $1,092 \mathrm{a}$ & $0,057 \mathrm{a}$ \\
\hline 4 & 80 & $34,5 \mathrm{c}$ & $0,402 c$ & $0,025 \mathrm{c}$ \\
\hline 5 & 100 & $0 \mathrm{~d}$ & Od & $0 \mathrm{~d}$ \\
\hline & CV (\%) & 4,5 & 9,5 & 6,7 \\
\hline & D.M.S. $1 \%$ & 7,5 & 0,134 & 0,007 \\
\hline
\end{tabular}

${ }^{1}$ Níveis de umidade do substrato em relação a capacidade de retenção

${ }^{2}$ Médias seguidas pela mesma letra, nas colunas, não diferem entre si pelo teste Tukey, a $1 \%$ de probabilidade.

Os resultados obtidos neste estudo, divergem dos citados por POPINIGS (1985), que observou altas porcentagens de emergência para a cebola, em solo franco e arenoso com níveis de umidade acima da capacidade de retenção no solo.

A germinação plena acontece em potenciais hídricos que variam com a espécie e o cultivar; PIANA (1980), observou maior porcentagem de emergência para o cultivar de soja Bragg a $-0,2 \mathrm{~atm}$. Valores ao redor de $-8 \mathrm{~atm}$ são considerados como limites para a germinação, para a maior parte das espécies cultivadas (YOUNG $e t$ al., 1983). A título de exemplo podem ser citados resultados de $-7,6 \mathrm{~atm}$ a $-10,0 \mathrm{~atm}$ para gramíneas forrageiras (WATT, 1982), de $-12,5 \mathrm{~atm}$ para milho (HUNTER \& ERICKSON, 1952) e de $-10,0$ atm para sorgo, trigo, cevada e milho (BODSWORTH \& BEWLEY, 1981).

Pelos testes de peso da matéria verde e seca de plântulas (TABELA 1), observou-se que os níveis de umidade de 40 e $60 \%$ apresentaram plântulas mais vigorosas. As regressões peso de matéria verde $(y)$ e peso de matéria seca $(y)$, em função dos níveis de umidade ( $x$ ) foram, respectivamente:

$$
\begin{aligned}
& y=-0,4922+0,0507 x-0,000464 x^{2} \\
& y=0,0297+0,001335 x-0,0000165^{2}
\end{aligned}
$$

Para o teste de frio, que avalia o vigor das sementes, recomenda-se que a umidade do substrato seja mantida a $70 \%$ ou $60 \%$ da capacidade de retenção, dependendo do tipo de solo (MARCOS FILHO et al., 1987). Já POPINIGS (1985), indica para o mesmo teste, a umidade do substrato de $60 \%$ da capacidade de retenção.

Observou-se alta emergência de plântulas a níveis baixos de umidade do substrato (20\%), o que se justifica em função do processo de germinação iniciar-se devido à rápida absorção de água pelos biocolóides, ocorrendo embebição de todos os tecidos da semente e expansão do tegumento envolvente. A força inicial de embebição, por parte da semente seca, pode ser muito grande (-500 a $-1.000 \mathrm{~atm})$ envolvendo a união da água às moléculas orgânicas. Com o progresso da hidratação das células, a força osmótica passa a atuar e a força de absorção de água torna-se menor, da ordem de -10 a -30 atmosferas (CARVALHO \& NAKAGAWA, 1983). Com o crescimento gradual da plântula, o nível de umidade de $20 \%$ mostrou-se insuficiente, para 
permitir adequado desenvolvimento da mesma, fato que pode ser constatado pelo peso da matéria verde e seca das plântulas (TABELA 1).

Existe um teor de umidade do substrato que possibilita o melhor desempenho das sementes, conforme pode ser observado neste estudo. Os resultados revelam a importância do teor adequado de água do substrato, para a germinação de sementes e estabelecimento de plântulas de cebola.

\section{CONCLUSÕES}

Para as condições do presente estudo, os níveis de umidade do substrato adequados para a germinação de sementes de cebola foram de $40 \%$ e $60 \%$ da capacidade de retenção, por possibilitarem melhor emergência e pesos da matéria verde e seca das plântulas.

\section{REFERENCIAS BIBLIOGRÁFICAS}

BODSWORTH, S.; BEWLEY, J.D. Osmotic priming of seeds of crop species with polyethylene glycol as a means of enhancing early and synchronous germination at cool temperatures. Canadian Journal Botany, Ottawa, v.59, p.672-676, 1981.

BRADFORD, K.J. Manipulation of seed water relations via osmotic priming to improve germination under stress conditions. Hortscience, Alexandria, v.21, n.5, p.1105-1112, 1986.

BRASIL, Ministério da Agricultura. Regras para análise de sementes. Brasília, Ministério da Agricultura e Reforma Agrária, 1992. 365p.

CARVALHO, N.M.; NAKAGAWA, J. Germinação. In: CARVALHO, N.M.; NAKAGAWA, J. Sementes ciencia, tecnologia e produção. 2.ed. Campinas: Fundação Cargill, 1983. Cap.7, p.107-143.

FRETZ, T.A.; READ, P.E.; PEELE, M.C. Plant propagation. Laboratory manual, Mineapolis: Burgess Publishing, 1979. 317p.

GRABE, A.R.; DANIELSON, R.E. Effect of $\mathrm{CO}_{2}, \mathrm{O}_{2}$ and soil moisture suction on germination of corn and soybeans. Soil Science Society of America Proceedings, Madison, v.29, p.12-18, 1965.
HUNTER, J.R.: ERICKSON, A.E. Relation of seed germination to soil moisture tension. Agronomy Journal, Madison, v.44, p.107-109, 1952.

MARCOS FILHO, J. Germinação de sementes. In: SEMANA DE ATUALIZAÇĀO EM PRODUÇÃo DE SEMENTES, 1., Piracicaba, 1986. Trabalhos apresentados. Campinas: Fundação Cargill, 1986. p.11-39.

MARCOS FILHO, J.; CÍCERO, S.M.; SILVA, W.R. Avaliação da qualidade das sementes. Piracicaba: FEALQ, 1987. 230p.

NORTON, C.R. Germination under flooding: metabolic implications and alleviation of injury. Hortscience, Alexandria, v.21, v.5, p.1123-1125, 1986.

PESKE, S.T.; DELOUCHE, J.C. Semeadura de soja em condiçōes de baixa umidade do solo. Pesquisa Agropecuária Brasileira, Brasilia, v.20, v.1, p.69-85, 1985.

PIANA, Z. Influências do tamanho da semente de soja (Glycine max (L.) Merril) e nível de umidade do solo na germinação e no vigor. Pelotas, 1980. 95p. Dissertação (Mestrado) - Escola de Agronomia "Eliseu Maciel", Universidade Federal de Pelotas.

POPINIGS, F. Fisiologia da semente. 2.ed. Brasilia: AGIPLAN, 1985. 289p.

SILVA, W.R. Relação entre disponibilidade de água, tratamento, fungicida e germinação de sementes de milho (Zea mays L.). Piracicaba, 1989. 113p. Tese (Doutorado) - Escola Superior de Agricultura "Luiz de Queiroz", Universidade de São Paulo.

WATT, L.A. Germination characteristics of several grass species as effected by limiting water potential imposed through a cracking black clay soil. Australian Journal Agricultural Research, Melbourne, v.3, p.223-231, 1982.

YOUNG, J.A.; EVANS, R.A.; ROUNDY, B.; CLUFF, G. Moisture stress and seed germination. Oakland, USDA/ARS, 1983. 41p. (USDA/ARS. Agricultural Reviews and Manuals. Western Series, 36).

Recebido para publicação em 07.01.94

Aceito para publicação em 21.08.94 